\title{
A study of Sinhalizations in Sinhala-English Mixed Discourse
}

\author{
Chamindi Dilkushi Senaratne \\ English Language Teaching Unit, Faculty of Humanities, University of Kelaniya \\ Kelaniya, Sri Lanka \\ E-mail: dilki@kln.ac.lk
}

Doi:10.7575/aiac.alls.v.5n.6p.10

Received: 26/07/2014

URL: http://dx.doi.org/10.7575/aiac.alls.v.5n.6p.10

Accepted: 22/09/2014

\begin{abstract}
Pronunciation plays a vital role in creating a language acceptable to all. This is also true in the case of Sri Lankan English (hereafter SLE). This study concentrates mainly on the phonological features of non-standard SLE, identified mainly by deviations in pronunciation of a few vowels and consonants. The objective of this paper is to analyze the terms characterized as non-standard by using Muysken's theory on Code Mixing. The proposed analysis will categorize elements into insertion and congruent lexicalization strategies. The study will analyze recorded speech of 20 urban bilinguals to obtain data. Self-assessment questionnaires will be used to determine attitudes towards phonologically marked items. Results will reveal that terms which are phonologically marked as non-standard. These phonologically marked items identified as Sinhalizations show more affinity to Sinhala phonology and are based on the speaker's first language. They are products of a grammaticalisation process.
\end{abstract}

Keywords: Sinhalizations, Code Mixing, grammaticalisation process

\section{Introduction}

The status of English ${ }^{\mathrm{i}}$ in Sri Lanka keeps on changing. It is as widely used as the Sinhala ${ }^{\mathrm{ii}}$ language. In many instances, the two languages are used simultaneously by speakers in informal conversations. Many describe English as a 'tool' in communication and others may opt to say it as a 'weapon' (Kandiah 1984: 117) used to stigmatize speakers. The mixing context between these two languages in Sri Lanka has brought about changes not only within iii these languages but also in the socio-economic status of the speakers. Furthermore, it has resulted in creating a mixed variety with many distinct linguistic features.

The subject of this study concentrates mainly on a certain phonological features of Sinhala which has a significant impact on English used in Sri Lanka. It is important to note that 'non-standard' English is defined mainly by the use of these few vowels and consonants by bilingual speakers whose familiarity with Sinhala becomes obvious due to phonological deviations from Standard English. In fact, phonetic variation in spoken English in Sri Lanka has received considerable attention as it identifies speakers as either 'standard' or non-standard'.

The aim of this study is to present the phonological characteristics that determine the linguistic status of Sinhala-English bilinguals in Sri Lanka and to analyze the terms characterized as 'non-standard' using Muysken's typology on Code Mixing (CM). The language varieties under study are spoken English and colloquial Sinhala, which are widely used in day to day activities in present day Sri Lankan urban society. These items are referred to as Sinhalizations ${ }^{\text {iv }}$.

\section{Sinhala in Sri Lanka}

Since the first permanent settlements of Ceylon, believed to be in the first millennium, Sinhala has developed with continuous contact with many Germanic, Indo-Aryan and Dravidian languages for over two millennia (Gair 1998: 3). The distinct features of Sinhala phonology, morphology and syntax owe much to this colorful historical background. The evidence of it is found in the rich array of vocabulary Sinhala language boasts due to a number of loans from languages it had come in contact with. Sinhala in Sri Lanka is spoken alongside Tamil, English, Malay and other languages. It is widely used in both formal and informal contexts. Table 1 lists the important milestones of the Sinhala language from the $4^{\text {th }}$ Century B.C. to 1978 taken from Senaratne (2009: 25).

Table 1. Development of Sinhala, from Senaratne (2009))

\begin{tabular}{|c|c|}
\hline Date & Key events \\
\hline $\begin{array}{l}\text { C. } 400 \text { BC Sinhala-Prakrit } \\
\text { Sanskrit influence }\end{array}$ & North Indian influence through long-distance trade. \\
\hline $\begin{array}{l}\text { C. } 250 \text { BC Pali and Sanskrit } \\
\text { influence }\end{array}$ & Arrival of Buddhism \& Jainism along with Brahmi inscriptions. \\
\hline 1505 Portuguese influence & $\begin{array}{l}\text { The first Europeans, the Portuguese, arrive in the island led by Francisco } \\
\text { de Almeida. }\end{array}$ \\
\hline 1592 & The Sinhalese moves their kingdom to Kandy ${ }^{16}$. \\
\hline
\end{tabular}


1602 Dutch influence

1660

1796 British influence

1815 Fall of the Kandyan Kingdom

1833

1948 Independence

1956 Sinhala, the only official language

1957

1972 Democratic Socialist Republic of Sri Lanka

1973

1978 Sinhala and Tamil as official national languages
The Dutch arrives in the island bringing with them a host of Dutch loans to the language.

The Dutch controls the whole island except Kandy.

The Dutch are ousted by the British. Ceylon becomes part of the British Empire. English is established as the only official language ${ }^{17}$.

British rule dominates the entire island except in Kandy. English is de facto the language of rule in the island.

The entire island comes under British rule with the fall of the Kandyan kingdom. The British begins to bring in more Tamil speaking people to work in the tea, coffee and coconut plantations.

English is made the official language of the country.

Ceylon receives independence from British rule. English still remains the only official language of Ceylon and remains the language of rule.

The Official Languages Act ${ }^{18}$ passed. The Official Languages Act No.33 of 1956 declared Sinhala as the 'one official language of Ceylon'.

Decision to teach in Sinhala, Tamil and English in the University of Ceylon from 1960 announced.

Sri Lanka becomes the Democratic Socialist Republic ending British dominance. The name of the country officially changed from Ceylon to Sri Lanka.

Language of the Courts bill passed in parliament.

The Constitution of the Democratic Socialist Republic of Sri Lanka declares Sinhala and Tamil as official national languages of the country. Sinhala and Tamil become official national languages and the languages of instruction in education. English no longer rules and is a link language. The Department of Official Languages ${ }^{19}$ was formed

Sinhala is diglossic (Gair 1968; Dharmadasa 1967; de Silva 1967) supporting distinct literary and colloquial varieties. Colloquial Sinhala has been receptive over the years to a host of borrowings from Pali, Sanskrit, Dravidian and European languages, and is used by all Sri Lankans, at all social levels. In essence, colloquial Sinhala cuts across class, education and social boundaries. Senaratne (2013) provides a comprehensive discussion of the effectiveness of colloquial Sinhala. Many sub-varieties of spoken Sinhala can be categorized under the colloquial variety of Sinhala. For easy reference, Table 2 from Senaratne (2009: 38) presents a general description of the three groups of SinhalaEnglish bilingual speakers relevant to this study.

Table 2. Categorization of Bilingual speakers, from Senaratne (2009)

\begin{tabular}{|c|c|c|c|}
\hline Speaker type & Social class & Comments & Characteristics of discourse in brief \\
\hline $\begin{array}{l}\text { Monolingual } \\
\text { English } \\
\text { speakers }\end{array}$ & $\begin{array}{l}\text { Upper and } \\
\text { elite class }\end{array}$ & $\begin{array}{l}\text { Forms a minority. Mostly belong } \\
\text { to the upper elite rich class and } \\
\text { hold high positions in society. } \\
\text { Speakers reside in cities and urban } \\
\text { areas. }\end{array}$ & $\begin{array}{l}\text { A few words in Sinhala mixed in conversation } \\
\text { with peer groups but mostly functions in English. }\end{array}$ \\
\hline $\begin{array}{l}\text { Bilingual } \\
\text { speakers }\end{array}$ & $\begin{array}{l}\text { Middle class } \\
\& \text { upper } \\
\text { working class }\end{array}$ & $\begin{array}{l}\text { Forms a substantial majority. } \\
\text { Mostly from the working class or } \\
\text { the middle class. Speakers } \\
\text { scattered around the country from } \\
\text { urban to rural areas. }\end{array}$ & $\begin{array}{l}\text { Speakers use English predominantly at work and } \\
\text { both English and Sinhala in general discourse. } \\
\text { These speakers form a special group as they can } \\
\text { move back and } \\
\text { forth from being a monolingual in English to a } \\
\text { monolingual in Sinhala and bilingual when the } \\
\text { occasion demands. }\end{array}$ \\
\hline $\begin{array}{l}\text { Monolingual } \\
\text { Sinhala } \\
\text { speakers }\end{array}$ & $\begin{array}{l}\text { Lower-class \& } \\
\text { working class }\end{array}$ & $\begin{array}{l}\text { Forms a majority and mostly } \\
\text { belong to the lower class. Speakers } \\
\text { reside predominantly in the rural } \\
\text { areas of Sri } \\
\text { Lanka and in urban and suburban } \\
\text { slum areas }{ }^{63} \text {. Most speakers are in } \\
\text { the low-income groups. }\end{array}$ & $\begin{array}{l}\text { Speakers use predominantly Sinhala in their } \\
\text { discourse with frequent inclusions in English. } \\
\text { These inclusions are register-specific. Many } \\
\text { English inclusions are nativized into Sinhala. }\end{array}$ \\
\hline
\end{tabular}




\section{The vowels}

Sinhala $^{\mathrm{v}}$ has 24 consonants $^{\mathrm{vi}}$ and 14 vowels as shown in Tables 3 and 4.The vowels of Sinhala are either 'long' or 'short', the difference being that of duration which is phonemic. Table 3 and 4 illustrate the short and long vowels, characteristic of Sinhala.

Table 3. The Sinhala short vowel chart based on Gair (1998: 7)

\begin{tabular}{cccc}
\hline & Front & Central & Back \\
\hline High & $\mathrm{I}$ & & $\mathrm{u}$ \\
Mid & $\mathrm{e}$ & $\partial$ & $\mathrm{o}$ \\
Low & $\mathrm{ae}$ & & $\mathrm{a}$ \\
\hline
\end{tabular}

Table 4. The Sinhala long vowel chart based on Gair (1998: 7)

\begin{tabular}{cccc}
\hline & Front & Central & Back \\
\hline High & i i & & u u \\
Mid & e e & əə & o o \\
Low & ae ae & & a a \\
\hline
\end{tabular}

The long vowels of Sinhala significantly influence the speaker of English in Sri Lanka. As a result, in place of the diphthongs used by BE or AE speakers, the SLE speaker will use long vowels in speech. This is regarded as a feature of the standard variety of SLE. Another variation worth mentioning is that vowels in spoken Sinhala occur not just as single units such as /ou/ 'yes', /ei/ 'may', /æi/ 'why', /koi/ 'where' but as vowel clusters in words such as /aiyaa/ 'brother', /ainə/ 'edge', /avuruddə/ 'year'. These vowel clusters are similar to diphthongs.

The vowel sounds of Sinhala are crucial to bilingual speakers in Sri Lanka. The standard and the non-standard speakers of English in Sri Lanka are mainly distinguished by the use of the back vowels /o/ and /o/. The non-standard variety of SLE is distinguished when speakers 'confuse' these two vowels. It is worthwhile to note that the 'confusion' is due to the non-existence of the back vowel / $/$ / in Sinhala phonology. Words such as 'call', 'ball' and 'morning' if not pronounced with the back vowel $/ \mathrm{\rho} /$ in predominant Sinhala sentences, are regarded in this study as results of the process of nativization. This variation takes place when integrating lone words in Sinhala utterances, giving rise to unexpected phonological patterns.

The variation in the use of the back vowels by speakers of English in Sri Lanka has resulted in stigmatizing speakers as 'non-standard'. The back vowel / $\mathrm{J}$ is a foreign sound and is a direct result of the contact between Sinhala and English languages.

\section{The consonants}

Table 5 presents the 24 consonants in Sinhala as given by Gair (1998: 6). Note that it excludes the foreign consonant /f/ which has joined colloquial Sinhala through contact situations.

Table 5. The Sinhala consonant chart based on Gair (1998:6)

\begin{tabular}{cccccc}
\hline & Labial & Dental & Retroflex & Palatal & Velar \\
\hline Stop & $\mathrm{p}$ & $\mathrm{t}$ & $\mathrm{T}$ & $\mathrm{c}$ & $\mathrm{k}$ \\
Stop & $\mathrm{b}$ & $\mathrm{d}$ & $\mathrm{D}$ & $\mathrm{j}$ & $\mathrm{g}$ \\
Pre-nasal & $\mathrm{mb}$ & $\mathrm{nd}$ & n̆d & & ng \\
Nasal & $\mathrm{m}$ & $\mathrm{N}$ & & $\mathrm{n}$ & $\mathrm{n}$ \\
approximant & $\mathrm{w}$ & & & & \\
Trill & & & $\mathrm{r}$ & & \\
Lateral & & & $\mathrm{l}$ & & $\mathrm{h}$ \\
Fricative & & $\mathrm{s}$ & & \\
Glide & & $\mathrm{y}$ & & \\
\hline
\end{tabular}

The speaker of English in Sri Lanka is bound to be influenced at some point in his/her conversation by the L1 (be it Sinhala or Tamil). With regard to consonants, contact with English has added the fricative /f/ to Sinhala. The addition results in producing an unexpected variation in pronunciation. Research on language contact phenomena and Contact Linguistics understand the replacement as errors as it indicates the speaker's non-familiarity with the languages concerned. The consonant $/ \mathrm{f} /$ is replaced by $/ \mathrm{p} /$ in most instances, as it is alien to native speakers of Sinhala. The replacement of $/ \mathrm{f} /$ with $/ \mathrm{p} /$ in the speech of English speakers has also resulted in class distinctions ${ }^{\mathrm{vii}}$ in Sri Lanka. In considering these unexpected, phonological patterns, CM reveals itself as one of the most significant mechanisms of 
language change in the Sri Lankan setting. It has changed the linguistic identity of the bilingual speaker in Sri Lanka. The replacement of /p/ with /f/ is defined as a feature of the 'non-standard' variety of English spoken in Sri Lanka.

The alveolar stops $/ t /$ and $/ d /$ in British English (BE) becomes retroflex stops in SLE in words such as 'dog' and 'tank'. Dental fricatives $/ \delta /$ and $/ \theta /$ of BE become dental stops in SLE, as in many other South Asian languages (Kachru 1986: 39). These variations in pronunciation are considered as features of the 'standard' variety of English spoken in Sri Lanka.

\section{English in Sri Lanka}

The previous sections emphasized the significance of Sinhala phonology on English ${ }^{\text {viii }}$ spoken in Sri Lanka. Sri Lankan English or Lankan English ${ }^{i x}$, used by Sri Lankans who speak English as their first language and Sri Lankans who are bilingual is one of the non-native varieties of English in the South Asian region. Tracing the development of the nonnative varieties of English, closely related to colonization, Kachru (1986: 88) points out that characterization of these Englishes ${ }^{x}$ cannot be presented in the native vs. non-native dichotomy. Accordingly, the non-native varieties of English are characterized by 'socio-cultural, motivational and functional' aspects (Kachru 1982a: 37). In characterizing these non-native varieties of English, it is important to consider what Kachru (1986: 89) refers to as the exo-normative (external) and endonormative ${ }^{\mathrm{xi}}$ (local) standards for the non-native Englishes.

English in Sri Lanka accordingly is marked by linguistically and culturally characteristic phonological, morphological and syntactic variations that sets it off from the native varieties of English such as BE or America English (AE). This study argues that these distinctions are mainly due to the interaction between Sinhala and English. The contact has resulted in a number of linguistic processes such as transfer from L1 to L2, collocations, hybridizations and most importantly, nativizations. This study argues that certain pronunciation patters with regard to vowels and consonants are results of nativization and analyses these unexpected variations as 'Sinhalizations' ${ }^{\text {,iii }}$.

This study proposes that some of the features associated with the non-standard type are results of the process of nativization, a highly productive process in language contact situations. These nativized elements are part of the repertoire of the Sinhala speaker. It is important to keep in mind that the standard features of SLE are modeled on BE and the non-standard features are based on Sinhala or Tamil phonological influence. English has become more Sri Lankan in the linguistic and sociocultural setting of Sri Lanka, and language mixing has contributed enormously to this new identity of SLE. In this backdrop, it is important to understand the influence of Sinhala on certain vowels and consonants of SLE.

\section{The phonology of SLE}

Table 6 presents some distinctions between English in Sri Lanka and BE vowels and consonants relevant to this study.

Table 6. Vowels and consonants of SLE relevant to CM (From Senaratne 2009)

\begin{tabular}{|c|c|c|}
\hline Consonants & Vowels & Comment $^{\text {xiii }}$ \\
\hline $\begin{array}{l}\text { The phoneme / } \mathrm{v} / \text { which is } \\
\text { a labio-dental } \\
\text { approximant is used in } \\
\text { place of both consonants } \\
\text { in } \mathrm{BE} / \mathrm{v} / \text { and } / \mathrm{w} / \text {. }\end{array}$ & $\begin{array}{l}\text { Long vowels /ee/ and /oo/ } \\
\text { in place of the BE } \\
\text { diphthongs /ei/ and /au/. }\end{array}$ & Sinhala has long vowels. \\
\hline $\begin{array}{l}\text { Dental stops for dental } \\
\text { fricatives } / ð / \text { and } / \theta / \text { in } \mathrm{BE}\end{array}$ & $\begin{array}{l}\text { The use of the front vowel } \\
\text { /i/ in front of consonant } \\
\text { clusters beginning with } / \mathrm{s} / \text {. }\end{array}$ & $\begin{array}{l}\text { Sinhala has dental stops and not fricatives. Hence, } \\
\text { voiceless /ð / as in 'think' and voiced / } \theta \text { / as in 'that' are } \\
\text { pronounced as stops (Meyler } 2007: \mathrm{xxi} \text { ). } \\
\text { Sinhala phonology inserts a high vowel in front of } \\
\text { consonant clusters beginning with /s/. }\end{array}$ \\
\hline $\begin{array}{l}\text { Retroflex stops for } \\
\text { alveolar stops } / \mathrm{t} / \text { and } / \mathrm{d} / \text { in } \\
\mathrm{BE} \text {. } \\
\text { The replacement of the } \\
\text { foreign consonant } / \mathrm{f} / \mathrm{with} \\
\text { the familiar } / \mathrm{p} / \text {. }\end{array}$ & $\begin{array}{l}\text { The replacement of the } \\
\text { back vowel /o/ with /o/. }\end{array}$ & $\begin{array}{l}\text { Sinhala has retroflex stops and not alveolars. } \\
\text { Sinhala does not contain the consonant /f/ but has } \\
\text { borrowed it as a result of the intense contact with } \\
\text { English. Sinhala also does not contain the back vowel } \\
/ \mathrm{o} / \text {. } \\
\text { In } \mathrm{CM}, / \mathrm{o} / \text { is retained. In nativizations, the vowel is } \\
\text { replaced by the familiar } / \mathrm{o} / \text {. }\end{array}$ \\
\hline
\end{tabular}


The variety of English used in Sri Lanka shares features with other South Asian 'Englishes' such as Indian English. The substitution of retroflex consonants with alveolars, the substitution of fricatives with stops (Kachru 1986:29) and the presence of a single $/ 1 /$ ( for both the dark and the clear $/ 1 /$ ) and $/ \mathrm{v} /$ for $/ \mathrm{v} /$ and $/ \mathrm{w} /$ of BE, is characteristic of SLE phonology. It is worth mentioning that these variations are considered characteristic of the 'standard' variety of English spoken in Sri Lanka.

On the other hand, the incorporation of the high vowel in front of consonant clusters $/ \mathrm{sk} /, / \mathrm{sp} /, / \mathrm{sm} / \mathrm{and} / \mathrm{st}^{/ \mathrm{xiv}}$, when pronouncing words such as 'school', 'spoon', 'smile' and 'station', is considered a feature of the 'non-standard' variety. This study argues that if these items occur as lone lexical items in predominant Sinhala utterances ${ }^{\mathrm{xv}}$, based on Muysken' typology of CM, they are results of the process of nativization. The speaker has used the grammar available to him/her to pronounce the words. This study terms them as 'Sinhalizations' as they are different to borrowings and code mixes (Senaratne 2013). In this sense, analyzing these lone lexical items as errors is not plausible. In patterning with Sinhala phonological rules, English consonant clusters that begin with /s/ are preceded by the vowel /i/ when they occur wordinitially in predominant Sinhala utterances.

According to Senaratne (2009: 237) unlike borrowings, which are easily identifiable, Sinhalizations cause pronunciation deviations and impact listener perception of the speaker. When using borrowings in speech, listeners perceive speakers as 'fluent speakers of Sinhala'. A negative perception is indicted when speakers use 'Sinhalizations' even though it may be in just one or two words. As discussed earlier in this study, Sinhalizations are mostly identifiable by the front close vowel prefix /i/ which follows consonant clusters beginning with $/ \mathrm{s} /$, the replacement of $/ \mathrm{f} /$ with $/ \mathrm{p} /$, the replacement of $/ \mathrm{o} /$ with $/ \mathrm{o} /$ and the deletion of $/ \mathrm{s} /$ word finally. This study suggests that the replacements cannot be categorized as errors if they occur in Sinhala utterances. The Sinhala vowel system does not contain the back vowel $/ \mathrm{J} /$ and therefore, most native speakers use the vowel that is in their L1 to pronounce English words containing the vowel / o/. The speaker is simply using the phonological rules that are already within him/her to pronounce the English lexical items.

Finally, the argument is that if the rules are based on the speaker's L1, the alien element is either a borrowing or a Sinhalization, results of the process of nativization. Hence, can such patterns in dominant Sinhala utterances ne analyzed as errors? It is a plausible argument that the familiarity with /o/ may result in the replacement or overuse of $/ \mathrm{o} /$ with $/ \mathrm{o} /$. Since $/ \mathrm{o} /$ is an alien sound to L1 speakers of Sinhala, its occurrence in lone lexical items in dominant Sinhala utterances can be categorized as a result of the lack of phonological awareness of English in the speaker. Hence, the occurrence of $/ \mathrm{J} /$ can be analyzed as an error, if it occurs in dominant Sinhala utterances, as it reveals the speaker's lack of 'awareness' or familiarity with English phonological patterns and accepted pronunciation patterns. Another argument is that the unexpected pronunciation is not based on his/her L1, hence, analyzing such deviations as errors is plausible. Simply, if the unexpected pronunciation in lone English lexical items is not based on the speaker's L1, then it is defined as an error in this study.

\section{Code Mixing and theories}

The mixed code has effectively equipped the Sinhala speaker to meet the challenges of the present. As a result of Sinhala mixing with English, a mixed variety has emerged. It is evident that the mixed discourse displays more affiliations to Sinhala than to any other language, simply due to its usage. Furthermore, the structural features of SLE indicate the overall influence of colloquial Sinhala on the variety of English spoken in Sri Lanka. The facts indicate the dominant role of colloquial Sinhala. Colloquial Sinhala is the most influential language on other language varieties, spoken in Sri Lanka. Research on English used in Sri Lanka relevant to this study have been conducted by Swigart (1992), Fernando (2003), Fonseka (2003) and Abewickrama (2007). The contact situation between Sinhala and English in Sri Lanka is comprehensively discussed in Senaratne $(2009,2011,2013$ a and 2013b) where significant structural differences categorize the mixed discourse of urban bilingual speakers into four types: namely borrowings, hybrids, Sinhalizations and code mixes. This study further reiterates the findings of research by Senaratne (2009) in code mixing between Sinhala and English.

To analyse the data, this study makes use of theories on language contact situations put forward by Kachru (1983), Myers-Scotton (1992) and Muysken (2000). Theories on nativization by Kachru will shed light on many mixing patterns prevalent in the Sinhala-English mixed corpus. Myers-Scotton's 'markedness' model will be used to identify how bilingual speakers 'phonologically' mark the code to indicate their linguistic identity. Muysken's typology on CM will be used to analyze the variety of mixing patterns used by the urban bilingual.

In any analysis of 'non-standard' linguistic features of a language, it is important to consider how 'error' are defined, in language mixing contexts. Kachru (1983: 2) defines a 'mistake' as unacceptable on several accounts. A mistake is an 'unEnglish' term which is not the result of a systematic, grammatical or 'productive process' such as nativization, neutralization and hybridization. Observe that in this definition, all the mixing processes such as nativization, neutralization and hybridization are referred to as grammatical processes.

Having said that, he observes that these dichotomies are not always clear-cut and hence defining a 'mistake' from a 'deviation' is not that easy. Further, defining what he meant by 'deviant', Kachru (1986: 29) suggests that a 'deviation' can be 'different to the norm, ${ }^{\text {xvi }}$ but is a result of a 'productive and systematic process' unlike a mistake. Kachru observes that the nativization, hybridization and neutralization processes result in the lexical and stylistic innovations and are characteristic of the non-native varieties of English in post-colonial societies. For Kachru, it is through CM that all these productive and grammatical processes take place. Elements from the donor language are integrated into the base language and the donor language acts as an additive source of linguistic material in the development of a 
specialized register. Language deviation to him is a process that has resulted in language varieties in post-colonial societies. Deviations distinguish the post-colonial varieties of English from the native varieties of English and are not always indicative of non-standard language varieties. In fact, deviations are different to mistakes.

Myers-Scotton's (1993) markedness model proposes that speakers have a 'sense of markedness' in the use of the linguistic codes available to him/her and that all code choices can be explained in terms of speaker 'motivations' (Myers-Scotton 1993: 109). Accordingly, speakers make the 'unmarked' choice for safer and simpler reasons. MyersScotton suggests that the 'umarked' code generally acquires 'fewer distinctive features' and represents 'greater frequency' (Myers-Scotton 1993: 80). In essence, the language that is less expected to be used at a given interaction with an interlocutor represents the 'marked code choice'.

In Muysken's (2000) CM typology, he talks of three strategies: insertional, alternational and congruent lexicalization. Muysken's (2000) CM typology provides a satisfactory explanation to the diversity prevalent in bilingual discourse. In his framework, he admits that there is no single borrowing strategy just as there is no single mixing strategy. Describing three mixing strategies as characteristic of bilingual speech, Muysken explains that borrowing patterns are prevalent in insertional, alternational as well as CL mixing strategies.

The strategies are linked to each other. In his analysis involving SVO-SVO to SVO-SOV contact situations, language mixing display both constrained (insertion and alternation) and unconstrained (CL) mixing patterns. In insertional mixing, patterns reveal a non-nested a,b,a form whereas in alternational mixing chunks before the switch and after the switch have no link between them. The grammar of the two languages remain intact in alternational mixing. In CL mixing patterns, word internal mixing takes place.

\section{Methodology}

This study used a sociolinguistic questionnaire, a self- assessment questionnaire and a matched-guise technique to answer the following research questions:

- What are the structural properties of 'non-standard' English lone lexical items used in informal discourse by Sinhala-English bilingual speakers in Sri Lanka?

- Can deviations or variations be defined as 'non-standard'?

A sociolinguistic questionnaire was administered amongst 20 urban speakers in Colombo. Data was collected on the basis of this questionnaire which was designed to obtain specific information about language use, frequency of mixing and self-assessed language proficiency. The 20 selected respondents self-assessed that they were Sinhala-English bilinguals. As this study is between those languages, only those respondents were selected.

From the 20 respondents, the study selected 5 participants who were willing to go through a matched-guise technique. The main task of the 5 respondents was to identify whether the speaker was a standard or a non-standard speaker of English in Sri Lanka.

Five more speakers (from the same sample) were selected for the recording. Each speaker was given a list of words ${ }^{\mathrm{xvii}}$ in English which was read twice (the first list in standard pronunciation and the second with non-standard pronunciation). Bothe lists were read by the same speakers. The speakers selected for the matched-guise test were fluent speakers of English. The participants were asked to listen to both recordings and determine the language competency, the social status and other attributes.

The study deliberately selected words and not utterances or sentences, as it is words in isolation that cause a listener to determine the linguistic status of a speaker. It is hypothesized that speakers tend to focus on the mispronounced word, rather than the grammatical accuracy of the utterance as a whole when judging other speakers.

This study used Muysken's (2000) typology of CM to analyze the data collected from spontaneous speech of urban bilinguals. These lexical items were used for the matched-guise technique as well. Muysken's mixing strategies were used to analyze the structural properties of the additions (in the insertion of the /i/ in front of consonant clusters), the confusion of the back vowels in certain words. The following table presents a few words that were 'mispronounced' in the matched-guise technique by speakers and identified as features of the non-standard variety of English in Sri Lanka.

Table 7. A few words from the matched-guise test)

\begin{tabular}{lllll}
\hline$(1)$ & $(2)$ & $(3)$ & $(4)$ & $(5)$ \\
\hline$/ \mathrm{o} /$ & $/ \mathrm{o} /$ & $/ \mathrm{i} /$ & $/ \mathrm{f} /$ and $/ \mathrm{p} /$ & License \\
opportunity & cold & School & file & confidence \\
call & hole & Smart & airport & pension \\
saw & hold & Stop & fight & Shroff \\
cough & more & space & pavement & Cell phone \\
\hline
\end{tabular}

In Table 7, column (1) and (2), the back vowel confusion can be attributed to the non-familiarity with $/ \mathrm{s} /$ and due to this, speakers tend to overuse /o/. The overuse is a result of a grammatical process. However, analyzing the misuse of $/ \mathrm{o} /$ as an error is plausible. Here, the speaker phonologically marks the word being used which is indicative of the non- 
familiarity with the acceptable pronunciation. When the words listed in Table 7 were mispronounced, all the respondents identified the usage as a feature of the non-standard variety. Most of the respondents ticked the profession of these speakers as housemaids, domestic workers or laborers. Hence, data reveals that Sinhalizations are associated with low socio-economic groups. These results corroborates the findings in Senaratne (2009: 82) indicated in Table 4.10 .

\section{Analysis of data}

Results reveal that terms which are defined as non-standard are 'phonologically marked'. These phonologically marked items identified as Sinhalizations show more affinity to Sinhala phonology and are based on the speaker's first language. They are products of nativization which is a grammaticalisation process as defined by Kachru. This study analyses the confusion with the back vowels as a 'mistake' or 'error' if they take place in utterances where the matrix is English. If they occur in Sinhala dominant utterances they 'cannot be analyzed as errors as the speaker is using the grammar available to him/her to pronounce the lone lexical items (Senaratne 2013). The plausible argument is that if the grammar for the utterance is provided by one particular language, then the relevant rules (phonological, morphological and syntactical) need to be maintained. The moment a speaker deviates from a grammaticalisation process, an error or a mistake occurs.

The analysis of nativizations reveals that borrowings (Senaratne 2012) and Sinhalizations show a closer affinity to Sinhala. This is indicated most often by phonologically and lexically marked lone items. The more phonologically marked the lexical item is, the lower the social standing it signals in the eyes of the competent bilingual in Sri Lanka, as indicated in the matched-guise test results. Based on the findings, this study proposes a re-analysis of features of nonstandard features of English spoken in Sri Lanka.

By using Muysken's CL mixing pattern, Sinhalizations display the following structural properties: addition of a front close vowel prefix, the replacement of $/ \mathrm{f} / \mathrm{w}$ wh $/ \mathrm{p} /$, the replacement of $/ \mathrm{o} /$ with $/ \mathrm{o} /$ and the deletion of $/ \mathrm{s} /$ word finally. Where there are additions in the process of borrowing, there are replacements and reductions in the process of Sinhalization. Word internal mixing in Sinhalization is influenced by the phonological rules of the L1 and is rulegoverned. In addition, many English fricatives are deleted word-finally (Table 7). Governed by Sinhala phonology, Sinhalizations tend to be considered as errors or mistakes by fluent bilingual speakers.

\section{Conclusion}

By using CM theories, this study revealed that the phonology of Sinhala has a significant impact in identifying and distinguishing the non-standard features of English spoken in Sri Lanka. This study terms these few lexical items as Sinhalizations. Note that the variety of SLE is distinguished from BE and the non-standard variety of SLE mainly by phonological means. Socially, Sinhala phonology plays an even greater role in assigning linguistic identities to speakers. It isolates the non-speaker of English from speakers of English in Sri Lanka. In addition, pronouncing lone lexical English items using Sinhala phonology stigmatizes the native Sinhala speaker. It is important to note that Sinhalizations are a part of nativizations and are results of a grammatical process.

\section{References}

Abeywickrama, P. (2007). Do We Codeswitch or Codemix in Sri Lanka? Journal of Multicultural Discourses, 2(1), 6377.

De Silva, M. W. S. (1967). Effects of purism on the evolution of the written language. Linguistics, 31: 5-17.

Dharmadasa, K. N. O. (1967). Spoken and written Singhalese: a contrastive study. M.Phil thesis. University of York.

Dissanayake, J. B. (1991). The structure of spoken Sinhala 1: sounds and their patterns. Maharagama, Sri Lanka: National Institute of Education.

Fernando, S. (2003, November). The vocabulary of Sri Lankan English: Words and phrases that transform a foreign Language into their own. In 9th international conference on Sri Lankan Studies, Matara (pp. 28-30).

Fonseka, E. G. (2003, November). Sri Lankan English: Exploding the fallacy. In 9th international conference on Sri Lankan Studies, Matara (pp. 28-30).

Gair, J. W. (1968). Sinhalese diglossia. Anthropological Linguistics, 10, 8: 1-15.

Gair, J.W. (1998) Studies in South Asian linguistics - Sinhala and other South Asian Languages. Oxford: Oxford University Press.

Kachru, B. B. (1982). Models for non-native Englishes. In B. Kachru ed., 3: 48-57.

Kachru, B. B. (1983). The Indianization of English: The English language in India. Oxford: Oxford University Press.

Kachru, B. B. (1986). The alchemy of English: The spread, functions and models for non-native Englishes. Oxford: Pergamon Press.

Kandiah, T. (1980). Disinherited Englishes. The case of Sri Lankan English. Navasilu, 3, Part 1, 75-89, and Navasilu, 4, Part 11, 92-113.

Kandiah, T. (1984). Kaduva: power and the English Language weapon in Sri Lanka. In Percy Colin-Thome and A. Halpe eds., Honouring E.F.C. Ludowyk: Felicitation Essays. Colombo: Tisara Prakasakayo, 117-154. 
Kandiah, T. (1987). New varieties of English: The creation of the paradigm and its radicalization. Navasilu, 9, 31- 40.

Myers-Scotton, C. (1993). Social motivations for code-switching: evidence from Africa. Oxford: Clarendon Press.

Muysken, P. (2000). Bilingual speech: a typology of code-mixing. Cambridge: Cambridge University Press.

Senaratne, C. D (2013a). The dominant language and mixing patterns. Vistas Journal. The Open University of Sri Lanka.

Senaratne, C. D. (2013b). Borrowings or code mixes? The presence of lone English nouns in mixed discourse. Journal of the faculty of humanities. Faculty of Humanities.

Senaratne, C. D (2011). Discourse strategies of Sri Lankan bilinguals. S Godade Publishers.

Senaratne, C. D (2009). Sinhala-English code mixing in Sri Lanka. A sociolinguistic study. The Netherlands Graduate School of Linguistics. LOT publications.

Swigart, L. (1992). Two codes or one? The insiders' view and the description of codeswitching in Dakar. Journal of Multilingual \& Multicultural Development, 13(1-2), 83-102.

\section{Notes}

${ }^{\mathrm{i}}$ English is legislated as a link language. It holds the key to upward social mobility and is a symbol of power and prestige.

${ }^{\text {ii }}$ Sinhala is one of the legislated official national languages and is spoken by about $82 \%$ ii of the population in Sri Lanka. Sinhala is legislated as a medium of instruction in education and the language of written work in the government.

iii Emphasis is the author's.

${ }^{\text {iv }}$ See Senaratne (2009)

${ }^{v}$ Characteristics of spoken Sinhala are different from written Sinhala. One of the most striking features of spoken Sinhala is the redundancy of subjects in certain contexts.

${ }^{v i}$ According to Gair's (1998: 6) classification, 24 consonants are identified in Sinhala phonology. Dissanayake (1991:

31) identifies 26 consonants in Sinhala phonology taking into consideration the foreign consonants.

vii The replacement of /f/ and /p/ and the back vowels /o/ and / $/$ are considered features of non-standard English in Sri Lanka. ${ }^{94}$

viii There are many terms to refer to the variety of English spoken in Sri Lanka such as Sri Lankan English (SLE) or Lankan English (Kachru 1986: 41).

${ }^{\text {ix }}$ Kandiah (1987: 31) refers to the variety of English used in Sri Lanka as 'Lankan English'. Also, see Kandiah (1980) for an analysis of English used in Sri Lanka.

${ }^{x}$ Emphasis is the author's. See Kachru (1983: 18) on new Englishes.

${ }^{x i}$ See Kachru (1986: 89)

${ }^{x i i}$ See Senaratne (2013) and Senaratne (2009)

xiii For Sinhala phonology, see Dissanayake (1991: 26-33)

${ }^{x i v}$ Kachru's (1986) analysis of phonological features of South Asian Englishes

${ }^{\mathrm{xv}}$ The matrix is provided by Sinhala

xvi 'norm' in this context refers to the language of the native English speaker ${ }^{5}$

${ }^{x v i i}$ The lexical items were selected from spontaneous speech that occurred in the public domain. 